\section{Sheila Apicella}

has for many years worked in

local government, primarily in customer services and then with standards to enable the electronic transfer of data to improve those services to the citizen. For the past 3 years she has worked as part of the esd-toolkit project team, where she has ventured into customer segmentation in Local Government to shape the way in which services are delivered more efficiently.

Nic Streatfeild

is recognised as a leading exponent and facilitator of e-government. After graduation, he joined the Ericsson Graduate Training programme, before moving to Cable \& Wireless. In 1996, on his return to the UK after working in government sectors for Cable \& Wireless in Australia, he became one of the founders of Rutland On Line, then one of the country's first community websites. Today, rol provides services to local authorities throughout the country.

Keywords: channel migration, cost reduction, customer satisfaction, data sharing, geodemographics, public sector

\footnotetext{
Sheila Apicella

Esd Ltd

Bon Marché Centre

Ferndale Road

London, SW9 8BJ, UK

Tel: +440 0769692989

E-mail: sheila.apicella@esd.org.uk

Nic Streatfield

rol Solutions Ltd

ROL House, Long Row, Oakham

Rutland, LE15 6LN, UK

Tel: + 441572756565

Fax: +44 1572756560

E-mail: nic.streatfeild@govmetric.com

Http: www.govmetric.com
}

\section{Direct, database and digital marketing practice in the government sector: Black hole or parallel universe?}

\author{
Sheila Apicella and Nic Streatfeild \\ Received: 5th November 2009
}

\begin{abstract}
This paper contributes to the discussion of whether direct, data and digital marking practice is as relevant to the public sector as it undoubtedly is to the commercial sector, albeit in support of somewhat different objectives. It examines two specific areas of data and analytic innovation to illustrate how local authorities are succeeding in achieving cost reductions and in improving customer satisfaction levels by migrating specific population segments to more appropriate contact channels. Despite their monopoly status for the supply of certain services, this paper argues that innovations in the way customer satisfaction is gathered, particularly for digital channels, can be used to identify improvements in service quality in conditions where competitive markets do not apply. This paper concludes that because they are non-competing, local authorities operate in a culture in which data relating to population segments, services and channels used, and on customer satisfaction, can only be used to achieve significant improvements in effectiveness where comparable information is pooled and accessed for benchmarking purposes. Journal of Direct, Data and Digital Marketing Practice (2010) 11, 302-316. doi:10.1057/dddmp.2009.42
\end{abstract}

\section{Context}

The practice of what is currently described as 'direct, data and digital' marketing is commonly assumed to be a set of activities that helps sustain the effectiveness of commercial and not-for-profit organizations. Evolving originally in the 1960s in catalogue mail order companies (such as Great Universal Stores), direct sales organizations (such as Reader's Digest) and financial services companies (such as American Express), this practice has subsequently extended through virtually all vertical market sectors in the commercial sector, so that today it plays a central role in the operation of leisure, retail, automotive and even fast moving consumer goods (FMCG) manufacturing organizations.

By contrast there is little evidence to support the proposition that such practices are relevant to the public sector. Public sector employees 


\section{Are techniques relevant to the public sector?}

\section{Key trends in public policy:}

\section{Shift from universal to means tested provision}

\section{League tables}

\section{Identification of populations 'at risk'}

tend as a rule not to be attracted by the Institute of Direct Marketing's (IDM's) training programmes. Public sector applications tend not to feature in the IDM's course material. This journal covers very few case studies from the public sector.

Should it therefore be concluded that the public sector, by its very nature as a 'universal' provider, is not a suitable environment for the application of direct, data and digital marketing practice - a 'black hole'? Or is the public sector just a late adopter of these techniques? Or are these techniques already used in the public sector but, because they are described using different terminology such as 'Social Marketing', do private sector practitioners fail to recognize the transferability of skills and techniques with their public sector counterparts whom they can easily treat as living in a 'parallel universe'?

The purpose of this paper is to support the contention that there is nothing inherent in the culture or environment of public sector organizations that renders direct, data or digital marketing inappropriate for reaching their objectives; that the sector may have been a late adopter of some of these techniques but is now a serious user of them; and that there are already examples of innovative practice in government that deserve to be brought to the attention of practitioners in the commercial sector.

Even to the most casual reader of the national press it is evident that there are a number of trends in how Britain is governed that have a bearing on the use of data and targeting in the government sector.

1. As a result of pressures to restrict increases in the overall level of taxation and in the overall level of public expenditure, successive governments have subjected an increasing proportion of service delivery users to various forms of means testing. The application of means testing necessarily requires service providers to collect far more information about service users than if services were provided on a universal basis.

2. Believing that 'market' pressures improve the standard of service delivery, government strategy in sectors that are difficult to privatize, such as health and education, increasingly relies on the publication and dissemination of performance statistics, for example league tables of schools, hospitals and police forces, the compilation of which requires service users to provide detailed information about their age, gender, ethnicity, occupational status and so forth.

3. Government spends increasing resources on 'surveillance' systems the object of which is to identify and punish citizens who in some way or other fail to abide by accepted rules.

Resources are therefore allocated to the identification of citizens posing the highest risk of, for example, engaging in terrorist activity, avoiding payment of TV licence fees, not declaring sources of income on benefit forms, not declaring income to HM Revenue and Customs, committing paedophile acts, avoiding registration in their capacity as landlords, traders, etc. Each of these campaigns requires not just the collection of raw information, but also the integration of data from 


\section{Saving money through preventative campaigns}

Evidence based policy diverse sources, in some cases including CCTV and number plate recognition systems, and the development of risk models that enable resources to be prioritized for cases representing the highest levels of risk. Each component of these systems bears a resemblance to stages in the private sector whereby communications are focussed on clients who, on the basis of previous behaviour, appear to represent best prospects taking into account the trade-off of potential revenues and likely servicing costs and bad debts.

4. In a number of sectors, the delivery of health and policing services being good examples, government recognises that the effectiveness of service outcomes can be significantly improved by encouraging service users to respond to preventative measures. This may involve encouragement to attend a diabetes screening centre or to improve the locks on doors of privately rented properties. Where investment in communicating these campaigns is justified by a high level of subsequent savings in delivery costs (treating the diabetes, attending the scene of a burglary), it benefits both likely victims and the general taxpayer if analytical techniques can harness data in such a way as to target preventative communications campaigns at those individuals where return on investment is likely to be highest.

5. In what has arguably become a 'post-ideological' age, government increasingly focuses on 'what works', and demands evidence from trials and tests to justify investment. To reduce the risk of investing in initiatives that 'do not work', government has become increasingly willing to seek advice from consultants, many of whom have extensive experience in the private sector. Where civil servants were once prejudiced against making use of techniques employed in the commercial sector, it could be argued that the evidence that there is a precedent of the use of a technique in the private sector now increases the likelihood that it will be adopted if included as a policy recommendation.

These increases in data availability; in systems (analogous to Customer Relationship Management [CRM] systems) such as the National Child Protection Register that link data from different sources; in risk-based models; and in demands for greater cost effectiveness coincide with an increased recognition of the potential role of new contact channels to deliver a means of both meeting service user preferences and delivering efficiency savings. Just as in the private sector, public service providers recognize that different service users have very different levels of access to and confidence in the use of different channels. ${ }^{1}$ The key to achieving these efficiency savings is the ability to predict the communications channels that are likely to be the most appropriate for reaching individual users of each of the different services government delivers.

Within the private sector, a key driver of CRM and other tools has been the desire to deliver a comprehensive view of the customer, taking into account all the different products and services that he or she may have purchased. CRM was and still is seen as a tool that enables 


\section{Extensive service portfolios}

\section{Multiple points of customer contact}

\section{Key differences between private and public sectors}

\section{Unequal costs of using different channels}

organizations to become more effective in co-ordinating sales across what were previously multiple product or departmental 'silos'.

The demand for and benefits of a 360-degree view of the service user is even more relevant to local authorities than it is to private companies. The number of clients of an individual local authority may seem relatively small to a national retailer. However, the range of different services that it delivers is arguably far more variegated than that offered by even the most diversified financial services or retail group. ${ }^{2}$

Likewise, the different types of environment and physical location at which the citizen makes use of local authority services - at a school, park, civic amenity site, car park, swimming pool, housing advice centre - are far more diverse than the types of physical location at which the citizen interacts with a bank - at a branch, at an ATM. The number of contact channels is likely to be equally diverse.

In addition, just as in his or her dealings with a private organization, the citizen is equally demanding that the government agencies with which he or she interfaces should, where relevant, be 'joined up' in terms of the view of the citizen that they hold. His or her time should not be needlessly wasted through being transferred from one operational department to another. In the public sector, forming a common view of the citizen is therefore as much in the interest of the service provider and the user as it is in that of the private sector.

Though it is possible to identify many similarities, it is obvious that there are a number of key differences of emphasis between operational environments in the two sectors.

In the private sector, although many operators adopt a multi-channel strategy to service clients, customers who have a particular preference for using a particular channel normally have the option to open an account with a supplier specializing in delivering through a specific channel. Local authorities, by virtue of being sole suppliers of specific services, need to take a more proactive role in researching the relative strength of their service proposition via different channels. This is because for many services, such as housing repairs or social services, they cannot rely on client defection rates as a proxy for customer satisfaction as would be the case for a commercial organization.

Additionally, because the revenue attaching to the delivery of a specific service is often set according to a formula by central government, local authorities appear to focus more than the private sector on the costs associated with servicing clients in different segments and via different channels, and rather less on differences in revenues generated. It could be argued that a greater focus on the analysis of the relationship between cost and market segments could contribute significantly to the profitability of private sector organizations.

A third key difference is that whereas in the private sector customer defection to a competing supplier can often be considered a consequence of customer dissatisfaction, for a local authority the level of satisfaction is a service objective in its own right, not as a 


\section{Sharing of evidence of 'what works'}

\section{Practice influenced by key reports}

\section{Profiling}

proxy for lost revenue. Therefore, the measurement of customer satisfaction is a more critical indicator of whether a service is delivered well or badly.

The monopoly status of the local authority as a local service provider does make it much easier for local authorities to make use of shared information services that enable contributing organisations to make comparisons between their own performance and that of others providing similar services through similar channels.

\section{The drive towards 'customer insight'}

Although customer profiling or segmentation has been used in the private sector for over 30 years, it is only since 1997 that government and local government have started to embrace the concept and understand its relevance to enabling resources to be targeted at those who are most in need of particular services.

The recommendations from the local government White Paper 'Strong \& Prosperous Communities' ${ }^{3}$ see reference place emphasis on the citizen. This and the Lyons Report's concept of 'place shaping' 4 - the idea that communities should not be subjected to 'one-size-fits-all' policies - and the Varney ${ }^{5}$ Report's advocacy of 'citizen insight' all support an increasing emphasis on citizen-centred service delivery.

In government, unlike the private sector, a key value of profiling and analysis is the ability that it can provide to identify aspects of the delivery of particular services that perform comparatively well or comparatively poorly in comparison with other service providers serving other geographic areas. Are response rates to public health campaigns to encourage measles, mumps and rubella (MMR) take-up higher or lower than in comparator authorities? Accessing equivalent comparator information, for example the proportion of respondents to a credit card mailing who are declined at the credit application stage, is less easy for commercial marketers. Often they will have to rely on the experience of consulting organizations to provide unofficial benchmarks as a result of their work with other players in the industry.

\section{The fundamental requirement for consistent activity and service code classification}

Before segmentation data can be used to facilitate comparisons with other local authorities, it is of course necessary to deploy a common set of definitions to categorize in detail the different services that local authorities deliver to their clients. The esd-toolkit is the result of an investment that central government recognized as being necessary if benchmark comparison of this type was to prove reliable. As a result of this investment a common set of codable categories has emerged over the past 5 years that has now been adopted by local authorities across England and Scotland to give a common language base when referring to services, channels and costs. This categorization forms the 


\section{'Nearest neighbour' analysis}

\section{Shared database of performance statistics}

basis for the Local Government Services List (LGSL). ${ }^{6}$ This categorization clearly improves the reliability of returns requested by central government, as well as benchmark comparisons between authorities.

In order to facilitate benchmark comparisons, the esd-toolkit has extended its remit so as to enable participating local authorities to share access to the effectiveness of their Social Marketing campaigns, as well as their overall performance. The performance of each of the 50 participating authorities in respect of each detailed service and through each channel (web, phone, face-to-face etc) has been established by uploading data directly from that local authority's CRM system or from records of users of individual services.

\section{Benchmarking as a performance management tool}

This service allows the local authority, for example, to identify the proportion of Council Tax payers who have been successfully persuaded to make payments via direct debit or the proportion of housing benefit enquiries that are resolved over the telephone as against visits to local authority advice centres. This information clearly provides benefits to participating local authorities regarding channels they could be using to a greater extent than they currently are for delivering specific services and hence identifying particular areas where cost savings could most easily be introduced.

The reporting systems associated with the esd-toolkit encourage local authorities not just to benchmark their own performance against the national average, but to compare themselves with 'nearest neighbour' analogues, that is, authorities whose population profile is most similar to their own.

To address the fact that the demographic composition of most local authorities is very different one from another, and to identify in more detail the individual service users who are most likely to respond to efforts to change their channel usage (and indeed to identify service users where this should not be an objective), the esd-toolkit ${ }^{7}$ encourages participating authorities to collect service user postcodes and to share information on the geographic profile of users by different channel/service combination, as well as costs by geodemographic type.

\section{Sharing information on activity and communications costs}

Currently, a major focus of the development of the esd-toolkit programme is to improve the accuracy with which information on costs can be integrated within the system. By undertaking a detailed audit of the costs per contact for different service delivery functions via specific communications channels, participating local authorities will increasingly be able to share information on the return on investment in terms of cost savings from transferring given numbers of transactions and service enquiries from one channel to another. 
Activity based costing

12 million transactions

\section{Early adopters of new transaction channels}

A more detailed 'Activity Based Costing' methodology is now also being trialled that will give a cost breakdown for each part of a service so that costs can be modularized to build up a picture of service delivery, demand, latent demand and performance.

\section{Informing customer access and channel strategies}

To date, the esd-toolkit has gathered information on over $12 \mathrm{~m}$ transactions, cross-referenced against the categories on the LGSL. Each participating local authority can view the customer breakdown for each service, the channel split and the propensity of customers to switch channels. When supplemented by the cost information, this informs the development of a customer access and channel strategy.

Clearly there is a drive among most local authorities to shift customers to cheaper channels. However, it is also worth noting the experience of one of the participating local authorities, the geodemographic profile of whose residents does not favour the construction of an all-singing-all-dancing website and is unlikely to be influenced by it. Certainly where the geodemographic profile indicates large numbers of residents in groups and types that would be willing to shift channel, local authorities have been successful in implementing a change programme. For example, where overlaid national aggregated data showed many residents living in geodemographic groups and types that had already adopted telephone banking, successful campaigns have seen increased take-up of direct debits, resulting both in operational savings and improved debt recovery.

Customer profiling is proving most successful when it is embedded in the organizational culture. It not only informs service delivery, customer access and equalities impact assessments, but also performance management when linked via the services list to the National Indicators that local authorities are required to report against as a measure of their effectiveness.

For example, recognizing that a citizen's time is valuable, a local authority can profile contacts that could have been avoided if the initial information had been clearer or the service had not failed in some way. This figure, a requirement of National Indicator 14, can be split out in esd-toolkit so that service failure can be improved upon and precious resources directed to those who need it most. Performance figures can also be put into context. For example, a local authority that has a large number of residents who are unlikely to recycle can use profile data to discover that it is more difficult for it to achieve recycling targets than for a local authority that has geodemographic groups and types more willing to participate in creating a green environment. Local authorities can also look up their demographic near neighbours to help them have a view on how others with similar citizen makeup are performing and delivering against the same targets (Figure 1).

The fact that many authorities are using the esd-toolkit's techniques means that there is a huge potential for benchmarking. 


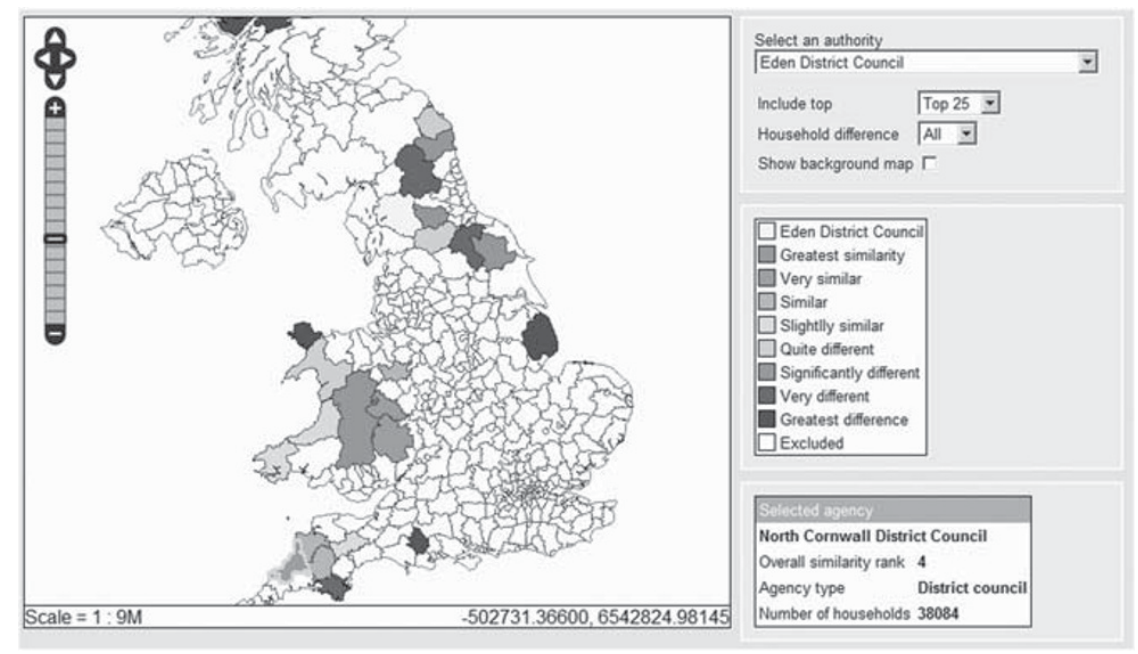

Figure 1: Map showing rural local authorities in England and Wales most similar in geodemographic make-up to the district of Eden

\section{Examples of insights}

'Nuggets' that have been discovered using this approach include:

- elderly customers were applying for and being issued disabled bus passes rather than the elderly person's pass (cost saving potential);

- there was a high take-up of 'freebees' from affluent groups (bus passes, loft insulation, heating allowance, free prescriptions, leisure facilities etc)/low take-up from those who have greater need;

- low library usage was to be expected from certain groups, but there were some surprises: where there was a high proportion of affluent groups, those who would not usually use libraries were taking up the service at a higher rate than the national average;

- in some areas there were high levels of face-to-face transactions or post contact where the profile indicated that the customer would be happy to use other (lower-cost) channels. This provided an opportunity for channel-change to less resource-hungry options without reducing customer satisfaction;

- rural communities were often 'missed out' as assumptions were made about affluent areas; drilling down into rural communities showed small pockets of deprivation; and

- profiling enabled some local authorities to understand why they were experiencing low take-up of online services. They had above the national average of groups and types who would be unlikely to use web. An action plan of how these groups might be supported could be drawn up along with a marketing plan.

\section{Benefits and limitations of channel migration strategies}

Migrating customers to lower-cost access channels is an understandably appealing proposition for organizations seeking to achieve significant cost savings. However, if local councils are indiscriminate in their drive to move citizens to self-serve, they run the risk of missing 


\section{Interconnectedness of services}

\section{Waste and recycling in South Tyneside}

\section{Shifting enquiries from contact centres to the web}

\section{Citizen satisfaction as a target}

opportunities to deliver a personalized service that may, in the long run, be more cost effective.

Just as is the case with high street banks, local authorities recognize that customer enquiries that are dealt with face-to-face - either in council offices or in the home - present officers with an opening to use their knowledge and experience to make a comprehensive assessment of the customer's needs. A simple enquiry about housing benefits might lead to a discussion about free school meals, funded childcare options, and ultimately to assistance with employment or training. This opportunity is even greater in an environment where different services providers work closely together, irrespective of the initial point of contact.

Nevertheless, appropriate channel migration can enable local authorities to save money or to free up resources, which can then be redeployed to more proactive work with those citizens most in need of facilitated access to services.

An example of this can be found at South Tyneside District Council. With pressure on key services rising as a result of the economic downturn, the council embarked on a project to migrate non-critical waste and recycling services to the web. Guided by customer insight information, the council redeveloped its online information and transactional services, and improved navigation and search on the website.

The Council used GovMetric, a service that captures customer feedback and interaction levels at the point of experience across all the primary access channels, to measure the impact of these improvements. The GovMetric data revealed that these improvements alone were not delivering the anticipated drop in calls to the contact centre. To address this, the council embarked on a 6-month awareness campaign, and within 1 month GovMetric showed that the number of customers using this part of the website to self-serve had increased from just 203 in October 2008 to 2,809 in November 2008. This increase persisted during the following months, during which time GovMetric also recorded a steady drop in the number of customers calling the contact centre with waste and recycling enquiries.

Using information on enquiry costs per channel, the Council calculated that this channel shift brought the estimated overall average per-transaction cost in this service area down from $£ 2.97$ in November 2008 to $£ 1.25$ in April 2009 - a drop of 58 per cent. It also freed up approximately $0.25-0.5$ full-time equivalent employees per annum in the contact centre, which provided resources that could be used in dealing with the increase in demand for critical services.

\section{The value of real-time customer satisfaction data as an indicator of service effectiveness}

Government organizations are no less concerned at the level of user satisfaction with their services than are organizations in the private sector. Over the past decade, customer satisfaction has become increasingly prominent in the way that central government measures 


\section{From feedback forms to automated measurement systems}

\section{The value of shared information systems}

\section{Content of feedback on satisfaction}

the performance of local government. In 2000, the first Best Value General Survey required all councils in the country to find out how satisfied local people were with the services that the council provided. This survey was repeated every 3 years until April 2008, when best value performance indication (BVPI) was replaced with a single National Indicator Set (NIS).

The NIS comprises 198 National Indicators, including 25 indicators that are informed by citizens' views and perspectives. Eighteen of these are determined by measuring citizens' views and perspectives collected through a single Place Survey that is administered by all local authorities every 2 years. However, the Department of Communities and Local Government (CLG) recognizes that local authorities will also continue to rely on their own methods of seeking direct feedback on services.

Until relatively recently, measuring customer satisfaction with local authorities has been synonymous with feedback forms and customer surveys. A sample of customers would be selected to take part in a detailed survey, which would typically take place in the weeks or months following the customer's interaction with the organization. Designing and administering effective surveys can be a costly process, and by the time the results are available to the organization they may already be out of date. Furthermore, because they tend to be run periodically, traditional surveys may fail to register the impact of specific organizational changes and unanticipated events. As a result of the time delay between the customer's contact with the organization and the survey, the experience is no longer fresh in the customer's mind.

As a result, local authorities are increasingly shifting towards feedback methods that continuously capture customer feedback at the point of experience. Techniques pioneered by GovMetric capture customer feedback in real time at the point of service experience across organizations' primary access channels - face-to-face, telephone and web. Unlike traditional sampled surveys, the service is made available to every customer via self-service interfaces such as kiosks, telephone interactive voice response (IVR) systems and web-based forms, and can also be extended to capture feedback relating to email and postal correspondence.

In a manner not dissimilar to the esd-toolkit, GovMetric operates a shared information service whereby it receives and processes data gathered by participating organizations relating to the total volume of customer interactions recorded by those organizations.

\section{Using customer satisfaction data to refine channel strategy}

The GovMetric question set is intentionally very short, meaning that it typically takes less than 1 minute for a customer to leave feedback. Customers rate their experience of the service that they received from the organization using the three GovMetric Smileys, corresponding to a Good, Average or Poor rating. Customers are also able to select one of four reasons for the rating selected. Where the interface device allows, 


\section{Consistently coded service categories}

\section{Telephone contact results in highest satisfaction levels}

\author{
Streets and parking \\ services about which \\ the citizen is least \\ satisfied
}

customers are also invited to leave free-text comments, and may also be asked supplementary questions, enabling participant organizations to collect data such as ethnicity relevant to the recording of information on diversity.

Interaction volumes for the face-to-face and telephone channels are typically measured and recorded by the organization using existing processes and systems, for example CRM, tick sheets etc. This data is then sent to GovMetric at scheduled intervals. Different organizations may have different principles for defining and measuring customer interactions, and not all customer interactions may be recorded by all organizations. The quality of the information could not be assured were it not for the fact that participants code interactions according to the Local Government Supplier List.

Interaction volumes for the web channel are calculated by GovMetric by applying the International Federation of Audit Bureaux of Circulation (IFABC) definition of a web visit ${ }^{8}$ to each organization's web logs.

Each customer rating or interaction is assigned to one of the eight pre-defined service categories that are measured by that organization. If the rating or interaction cannot be assigned to one of these categories, it is assigned to either the 'Other Service' category or the 'Not a Service' category.

Customer ratings across participating organizations are averaged to obtain an overall measure of satisfaction for each unique channelservice pair, or 'segment', for example Web-Benefits. A minimum number of feedback responses must have been collected by each organization in order to be included in this measure.

Data gathered by GovMetric from approximately 50 local authorities in England and Wales indicate that customer satisfaction is consistently highest on the telephone channel, scoring an average of $0.92 . .^{9}$ The web channel has historically been the poorest-performing channel with regard to customer satisfaction, but it is interesting to note that since the beginning of 2009, customer satisfaction with online services provided by participants has been steadily increasing, and currently matches that of the face-to-face channel at around 0.36. This reflects the work undertaken by many participating authorities in making improvements to their web channels as a result of the customer feedback gathered by GovMetric.

Across the different service areas, customers are typically seen to be least satisfied with streets and parking services, although this is probably not surprising given that a large percentage of these enquiries will relate to the payment of parking fines. Of more concern is the relatively low level of satisfaction with housing services, backing up anecdotal evidence that many councils are struggling to meet tenant expectations with regard to waiting times for social housing and response times for repairs.

On the other hand, waste and recycling and council tax typically achieve higher than average overall satisfaction levels. The effort put in by many of the participating councils in improving the online information for these services is a major contributory factor; for example, in May 2009, 57 per cent of the respondents that commented on the ease of finding information about waste and recycling online 


\section{Drivers of customer satisfaction}

\section{Translating feedback \\ into service improvement}

rated this factor as 'Good', compared to only 35 per cent of those commenting on housing services. This emphasizes the importance of an effective online service in raising overall customer satisfaction levels.

\section{Using real-time feedback to diagnose sources of dissatisfaction}

The most fundamental factors that affect customer satisfaction are universal - staff knowledge and friendliness, the speed with which a customer's enquiry is dealt with, and the effectiveness of any actions taken to deliver an outcome or solve a problem. Research has identified the following five key drivers of customer satisfaction with public services ${ }^{10}$ :

Delivery - The service delivers the outcome it promised and manages to deal with any problems that may arise;

Timeliness - The service responds immediately to the initial customer contact and deals with the issue at the heart of it quickly and without passing it on between staff;

Professionalism - Staff are competent and treat customers fairly; Information - The information given out to customers is accurate and comprehensive, and they are kept informed about progress; and Staff attitude - Staff are friendly, polite and sympathetic to customer needs.

The relative importance of these drivers may vary depending on the service or channel, and individual services or customer segments may have additional specific drivers. Both the drivers and their relative importance can be fine-tuned by surveying customers directly, or through reviewing customer feedback.

Any customer survey or feedback service should reflect these drivers. For example, the GovMetric question set, although intentionally very short, invites customers to select one of four reasons for the rating given, which broadly align to the drivers set out above. This ensures that customers are able to give feedback about the factors that are most likely to be important to them.

But how can local authorities translate this feedback into actual service improvement? It does not have to be complicated. Customer service champions should make sure that a review of the latest customer satisfaction data is a standard item on the agenda of team meetings, and the feedback should be discussed openly. Most importantly, customer service advisors should be asked for ideas on how to tackle customer issues.

Key findings and any subsequent actions that are proposed or underway should be circulated across the wider organisation, and may include suggestions for how specific service areas could make improvements. The customer services champion should make sure that someone takes ownership for every action, and should oversee its completion. If a continuous feedback service is in place, it will be easy to monitor the impact of any changes made. 


\section{Display the results}

\section{Publish the results}

Heavy snowfall in Milton Keynes

\section{Response to feedback}

\section{Shift in satisfaction resulting from change}

A powerful opportunity to improve reputation, and one that is often missed, is the chance to feed back to customers how their feedback is being used to deliver change.

Display the results in your offices. This could be in the form of posters, flyers or information on an LCD screen displayed in reception. It is essential that this includes some specific examples of the action taken as a direct result of customer feedback. Updating it punctually is absolutely vital - if it is allowed to become out of date then customers will lose confidence that their feedback is being listened to, and it can be difficult to win this confidence back. The frequency of updates is less important than the data being current - it is better to have a high-quality quarterly update than a brief weekly update that is several weeks out of date.

Similar information should be published online, paying particular attention to the changes that have been made to the website, which will be of particular interest to this group of customers. Again, it is crucial that this is kept up to date.

\section{Case examples of the use of real-time customer satisfaction data}

An example of the benefits of having a robust feedback system in place, and reacting quickly to customer feedback, can be found in the way Milton Keynes Council handled the heavy snowfalls in February 2009. The council was unprepared for the scale of the surge in website traffic, and the site failed on the first day of snow. The web team responded immediately, and by 9 am the team had removed unnecessary content and processes and successfully restored the service, enabling head teachers to log on to the website and register their schools as closed.

The following morning, members of the team sat down to review the customer feedback captured by GovMetric on the previous day. Large numbers of people were leaving negative feedback to say that the school closures information was confusing, because it was not clear whether the information was up to date.

As a result, the web team quickly amended the school closures page to incorporate 'last updated' information, and sent out reminders to head teachers advising them that they must list any changes to their schools' status promptly on the website.

On Wednesday, the council continued with its rapid response to customer feedback by posting improved gritting maps on the website, and also by publishing guidance information to aid school heads when making a decision on closure.

By Thursday, the GovMetric data was showing a clear improvement in customer satisfaction from citizens seeking information about council services during the crisis. That morning, the council received 28 customer comments relating to the school closures page, and an impressive 26 of these customers had rated the information as 'Good', the highest rating that can be given.

Julie-Ann Hammond, Web Content Manager at Milton Keynes Council, spoke about the vital role that customer feedback played 


\section{Responding to a crisis}

\section{0 councils now standardising data}

\section{Consistency}

\section{Advice of Audit Commission}

during the crisis, which saw levels of customer demand for council information remain high until well into the following week. 'Real time customer feedback enabled us to respond immediately during a period when the Council's resources, across a range of services, were put under severe pressure by the extreme weather conditions'.

'The majority came through the council's website at www.miltonkeynes.gov.uk, and in total we must have received almost 700 pieces of feedback during the week of bad weather, on topics ranging from school closures to bus services, recycling and waste collections'.

'We found was that as the snow crisis developed, we were able to quickly and effectively modify our council web pages in direct response to what our residents told us, delivering a measurable improvement in customer satisfaction, despite the adverse conditions'.

\section{The pooling of satisfaction data and the mechanics and benefits of benchmarking}

The ability to benchmark customer satisfaction data within the local government sector offers individual councils a context in which to understand their current performance, and valuable input into the process of setting meaningful targets and understanding trends.

To achieve a customer satisfaction benchmark, the data on which it is based must be standardized, ideally at the point of capture. The GovMetric service has made significant progress towards this goal by achieving a standardized set of services, channels and drivers that has been adopted by over 50 councils. Arriving at this standardized list was a 'grassroots' process that involved detailed consultation with practitioners, with the goal of focusing on service improvement, as opposed to a top-down measurement service.

As well as a standardized question set, there must also be consistency in the way that the service is implemented in individual organizations, from the number of customers using the kiosks to the way in which customers are asked for feedback on the telephone. One of the roles of the GovMetric user group is to monitor how the service is being used and, where possible, to align this across the group.

\section{Establishing the appropriateness of 'one-size-fits-all' strategies}

New ways of capturing, measuring and sharing customer satisfaction data certainly present an opportunity for local government to better understand the individual needs of its citizens and communities. However, the majority of councils have yet to fulfil the potential of customer insight, and work remains to be done in how councils make use of the wealth of intelligence now available to them. In its recent report Is there something I should know? the Audit Commission highlights that most councils do not use their data to inform key decisions, and are missing chances to improve services and cut costs as a result.

Nevertheless, looking at the results from GovMetric it is clear that, for now at least, a multi-channel approach is essential if the goal is to 


\section{Many key similarities between public and commercial sectors}

deliver services that satisfy individual citizens. Examining the feedback for a single webpage will often reveal polarized opinions from different customer groups. A webpage that cites nothing but a contact telephone number will be welcomed by one customer, while frustrating a websavvy citizen who expects to self-serve. Conversely, the very name 'e-services' may bewilder someone who has been used to paying their council tax bill every month at the cashier's desk.

\section{Conclusions}

Our conclusion it that the issues that underlie the drive to direct, data and digital marketing in the commercial sector are not dissimilar to those that drive innovation in local government. These include the demand for a joined up view of the customer/citizen; the understanding of population segments for which different communications strategies are appropriate; the demand of users for personalization and for a choice of contact and transaction channels; and the desire of suppliers to migrate service users to lower-cost channels where appropriate.

Whereas in a competitive market environment client retention and profitability are the key indicators of the success of such strategies in local government, a combination of cost efficiency compared with other authorities with a similar population profile and measures of citizen satisfaction are likely to prove more effective measures for gauging success or failure than the ballot box.

Although it would appear that local government benefits uniquely from its opportunity to share information via pooled databases, it would probably be a mistake to suppose that operators in the commercial sector do not find other methods of benchmarking their effectiveness against that of their competitors. However, access to benchmark data may offer an important motivation for continuous service improvement in a sector where this cannot be achieved through the normal play of market forces.

\section{References}

1. Transformational Government, available at http://www.hm-treasury.gov.uk/d/pbr06_varney_ review.pdf.

2. Experian. (2006) 'Putting citizens at the heart of government, London.

3. http://www.communities.gov.uk/publications/localgovernment/strongprosperous.

4. http://www.lyonsinquiry.org.uk/.

5. Varney Review, available at http://www.hm-treasury.gov.uk/d/pbr06_varney_review.pdf.

6. Department of Communities and Local Government, available at http://www.bitc.org.uk/ programmes/programme_directory/regeneration/underserved_markets/.

7. esd-toolkit, available at http://www.esd.org.uk/esdtoolkit/.

8. VISIT - A series of one or more PAGE IMPRESSIONS, served to a valid BROWSER, which ends when there is a gap of 30 minutes or more between successive PAGE IMPRESSIONS for that BROWSER. See http://www.ifabc.org/for more information.

9. On a scale of -1 to 1 , based on data gathered by GovMetric in the period January 2009 - May 2009.

10. Public services. 